\title{
Urodimento
}

REVISTA DE ESTUDOS EM ARTES CÊNICAS

E-ISSN 2358.6958

\section{A cena intimista em um projeto remoto de pesquisa e extensão universitária}

Heitor Martins Oliveira

Bianca Nascimento de Melo

\section{Para citar este artigo:}

OLIVEIRA, Heitor Martins; MELO, Bianca Nascimento de. A cena intimista em um projeto remoto de pesquisa e extensão universitária. Urdimento - Revista de Estudos em Artes Cênicas, Florianópolis, v. 3, n. 42, dez. 2021.

do) DOI: http:/dx.doi.org/10.5965/1414573103422021e0114

Este artigo passou pelo Plagiarism Detection Software | iThenticate 


\title{
A cena intimista em um projeto remoto de pesquisa e extensão universitária
}

Heitor Martins Oliveira ${ }^{1}$

Bianca Nascimento de Melo²

\begin{abstract}
Resumo
As noções de teatro de imersão, cena intimista, teatro neo-tecnológico e áudio-teatro perpassam um percurso em pesquisa e extensão universitária que iniciou antes, mas teve continuidade durante a pandemia de Covid-19. A cena intimista é um formato cênico que privilegia o encontro, a imersão sensorial e processos de desorientação quanto ao espaço, ao tempo e à presença. As medidas de isolamento social e a implantação das atividades acadêmicas emergenciais remotas ocasionaram um contexto específico de experimentação criativa, no qual elementos do formato cênico intimista foram ressignificados a partir das limitações e potencialidades das presenças telemáticas e virtuais. Em que pese as distinções entre experiências teatrais (presenciais) e experiências artísticas remotas, as mediações tecnológicas são adotadas neste projeto como dispositivos para imaginar uma possível cena intimista remota e produzir múltiplos registros do processo criativo.
\end{abstract}

Palavras-chave: Teatro de imersão. Cena intimista. Processo criativo remoto. Extensão universitária.

${ }^{1}$ Doutorado em Música (Composição) pela Universidade Federal do Rio Grande do Sul (UFRGS). Mestrado em Música (Composição) - Texas State University - San Marcos (EUA). Bacharel em Música (Regência) e licenciatura em Educação Artística pela Universidade de Brasília (UnB). Professor adjunto da Universidade Federal do Tocantins (UFT). heitor oliveira@uft.edu.br

(3) http://lattes.cnpq.br/2105146691371116 (D) https://orcid.org/0000-0003-0211-2789

Graduanda do curso de Licenciatura em Teatro pela Universidade Federal do Tocantins (UFT) nascimento.melo@mail.uft.edu.br

http://lattes.cnpq.br/1401637003277065 (iD https://orcid.org/0000-0002-4916-6226 
The intimate scene in a remote university research and extension project

\begin{abstract}
The notions of immersion theatre, intimate scene, neo-technological theater and audio-theater permeate a path in research and university extension that started before, but continued during the Covid-19 pandemic. The intimate scene is a scenic format that favors the encounter, sensory immersion and processes of disorientation regarding space, time and presence. The measures of social isolation and the implementation of remote emergency academic activities led to a specific context of creative experimentation, in which elements of the intimate scenic format were reinterpreted based on the limitations and potential of telematic and virtual presences. Despite the distinctions between theatrical experiences (in person) and remote artistic experiences, technological mediations are adopted in this project as devices to imagine a possible remote intimate scene and produce multiple records of the creative process.
\end{abstract}

Keywords: Immersion theater. Intimate scene. Remote creative process. University outreach.

\title{
La escena íntima en un proyecto remoto de investigación y extensión universitaria
}

\section{Resumen}

Las nociones de teatro de inmersión, escena íntima, teatro neotecnológico y audio-teatro permean un camino de investigación y extensión universitaria que comenzó antes, pero continuó durante la pandemia del Covid-19. La escena íntima es un formato escénico que favorece el encuentro, la inmersión sensorial y los procesos de desorientación respecto al espacio, el tiempo y la presencia. Las medidas de aislamiento social y la implementación de actividades académicas de emergencia remota llevaron a un contexto específico de experimentación creativa, en el que se reinterpretaron elementos del formato escénico íntimo a partir de las limitaciones y potencialidades de las presencias telemáticas y virtuales. A pesar de las distinciones entre experiencias teatrales (presenciales) y experiencias artísticas remotas, en este proyecto se adoptan mediaciones tecnológicas como dispositivos para imaginar una posible escena íntima remota y producir múltiples registros del proceso creativo.

Palabras clave: Teatro de inmersión. Escena íntima. Proceso creativo remoto. Extensión universitaria. 
Este ensaio aborda um percurso de construção de conhecimento no contexto da pesquisa e extensão universitária, abarcando principalmente noções como teatro de imersão, cena intimista, teatro neo-tecnológico e áudio-teatro. Assumimos a própria prática artística e as reflexões construídas a partir dessa prática como elementos de uma metodologia que inclui ainda a pesquisa bibliográfica e o diálogo com outras propostas e processos artísticos e formativos. A questão central que o texto busca abordar é: como construir uma prática artística remota a partir do diálogo com a noção de formato cênico intimista?

Embora a ênfase do texto seja sobre a realidade de um projeto de pesquisa e extensão universitária no contexto do ensino emergencial remoto, entendemos que os questionamentos suscitados por esse momento exigiram retomar e reavaliar conceitos e práticas que o antecedem. Assim, o percurso de construção de conhecimento aqui apresentado e discutido pode ser compreendido em dois movimentos. O primeiro movimento é do teatro, entendido como campo artístico estabelecido, para a cena intimista, entendida como formato cênico contemporâneo ligado ao teatro de imersão e cuja genealogia está associada ao teatro ambiental e aos happenings. Esse primeiro movimento foi iniciado presencialmente, antes das medidas preventivas de isolamento social, mas a reflexão sobre as práticas às quais se refere foi consolidada já em meio à pandemia de Covid-19 e às perplexidades por ela suscitadas. O segundo movimento é das práticas cênicas presenciais para as práticas artísticas remotas, realizado integralmente no transcurso da pandemia. Em ambos os movimentos, o fio condutor é a prática artística, construída a partir da autoficção, que admite o desenvolvimento de distintos produtos a partir de um mesmo impulso criativo.

O texto está organizado em duas sessões que abordam, respectivamente, cada um desses movimentos, por meio de uma escrita que mescla o relato de nossas experiências ao diálogo com um recorte bibliográfico e com outros criadores. 


\section{O formato cênico intimista}

Nosso interesse pela criação cênica intimista teve como marco inicial a participação em um intercâmbio artístico com o Sleepwalk Collective, uma companhia de arte ao vivo e teatro experimental que trabalha desde 2006 entre Espanha e Reino Unido. Neste intercâmbio, realizado na cidade de Palmas (TO) em 2018, o grupo convidado trouxe o espetáculo The Sirens vis-à-vis (2009) ${ }^{3}$, apresentado a um(a) espectador(a) por vez, e ofertou a oficina A cena intimista e outros formatos cênicos. No ano seguinte, essa experiência foi tomada como ponto de partida para formulação do plano de trabalho em iniciação científica intitulado Processo de criação em cena intimista: narrativas de uma artistapesquisadora em formação.

A primeira parte do projeto foi desenvolvida com suporte de um grupo de estudos e práticas artísticas, composto pela estudante de graduação e bolsista de iniciação científica Bianca Nascimento de Melo e três docentes do Curso de Licenciatura em Teatro da Universidade Federal do Tocantins: a professora doutora Bárbara Tavares dos Santos, o professor mestre Marcial de Asevedo e o professor doutor Heitor Martins Oliveira, sendo o último orientador da pesquisa. Cada integrante desenvolveu uma cena e as reflexões sobre a prática artística, bem como as discussões teóricas, foram feitas em conjunto, agregando valor aos relatos da pesquisa e ao desenvolvimento das práticas.

Nesse primeiro momento, a construção conceitual e criativa se movia das experiências anteriores dos integrantes do grupo para a compreensão da noção de cena intimista como formato cênico relacionado ao teatro de imersão. No formato tradicional de teatro, o espaço físico, quase sempre, tem o poder de determinar o espaço do acontecimento teatral separando-o do espaço destinado ao(à) espectador(a). Essa separação acontece através do

espaço liminar: o que marca a separação (mais ou menos nítida, mas sempre inalienável) entre o palco e a plateia, ou entre o palco e a coxia. 
A liminariedade é marcada com maior ou menor intensidade: ribalta, velas, "círculo de atenção" que o ator traça mentalmente para se isolar do olhar do outro (Pavis, 1996, p.142).

A cena intimista, entretanto, como o próprio nome já revela, é um trabalho que leva em conta a proximidade com o(a) espectador(a) e tem como premissa um encontro, uma experiência compartilhada entre o(a) artista e o público. De modo geral, as obras que adotam esse formato são apresentadas para um número pequeno de pessoas, ou mesmo um(a) único(a) espectador(a). Não se trata apenas de um teatro em pequena escala, mas sim de uma abordagem de certos elementos da experiência teatral que, para ser melhor compreendida, deve ser contextualizada nas práticas cênicas contemporâneas.

A maneira que o(a) espectador(a) vivencia a experiência artística está intimamente ligada à maneira que os elementos da experiência teatral são apresentados. No teatro tradicional, além da separação do espaço do(a) ator(atriz) e do(a) espectador(a), também existe uma convenção social de como o público deve se portar diante da representação. O público apenas assiste a obra e, apesar de ser emocional e cognitivamente estimulado pelas sensações dos signos teatrais, não expressa isso de maneira que atravesse o acontecimento cênico.

O espectador de teatro (adulto, pelo menos), sobretudo em relação ao teatro de texto, raramente está autorizado a manifestar em voz alta e de corpo e alma suas impressões, reações e comentários; espera-se dele que aguarde o fim da representação para exprimi-las (Pavis, 1996, p.6).

No contexto do formato cênico de imersão, esse distanciamento espacial entre obra e espectador(a) perde importância, visto que uma das características desse formato é a criação de um encontro próximo com o(a) espectador(a). Preza-se pela proximidade em um caráter que não só autoriza, mas incentiva que o(a) espectador(a) interaja com a obra e, portanto, deixe de lado a convenção social de comportamento estabelecida no formato tradicional de teatro. É imprescindível, no formato intimista, que o(a) espectador(a) esteja dentro do espaço cênico da obra, que seja elemento fundamental da montagem e não apenas participante passivo. O processo de criação nesse formato parte fundamentalmente da ideia 
de criar uma experiência sensorial para o outro, conforme articula Iara Solano, uma das artistas do Sleepwalk Collective:

\begin{abstract}
Mas, o que resume muito o que deve conter uma peça de formato intimista, o vis-à-vis, é criar uma experiência para o outro, para o público, que neste caso é uma pessoa. É mais sensível porque pode controlar o todo, pode manipular o todo de uma forma muito direta. Mas, não se trata de fazer como outros chamam um "microteatro", ou vou fazer uma estreia para ti e você é testemunha. Não, há de mudar os papéis, os papéis não podem ser os mesmos que na cena mais tradicional. É muito importante que haja uma transformação, que o público tenha uma experiência, que o público esteja ativo tanto mentalmente, como em muitos casos também fisicamente. Estão participando dessa intervenção, é uma parte íntegra, uma parte fundamental da peça. Se não houver público, a peça não poderá existir (Solano, 2020, informação verbal).
\end{abstract}

Portanto, a inserção do(a) espectador(a) no espaço cênico não é apenas uma questão de proximidade, mas está relacionada a uma transformação também do papel do ator contemporâneo, que "não é mais encarregado de mimar um indivíduo inalienável: não é mais um simulador, mas um estimulador" (Pavis, 1996, p.55). Nessa linhagem da criação cênica contemporânea, o(a) espectador(a), por sua vez, é convidado(a) a uma experiência distinta:

Uma vez tocado não somente pela graça da arte teatral mas também pelo corpo do ator/atriz, o espectador modifica radicalmente sua abordagem do espetáculo, escapa o cálculo frio do olho geômetra, entra em um mundo de sensações que são, por vezes, também acompanhadas de reflexões abstratas (Pavis, 1996, p.184).

Ao tratar dessas proposições teatrais, Pavis (1996) refere-se ao teatro ambiental de Schechner (1994, p.xix) que partia de um repensar das distinções tradicionais entre vida e arte. Assim, o teatro ambiental pode ser entendido como parte de um contínuo que vai do teatro ortodoxo a eventos e manifestações públicas, passando pelos happenings inter midiáticos, como aqueles concebidos por Allan Kaprow4. A abordagem do teatro ambiental, assim como a dos

${ }^{4}$ Allan Kaprow (1927-2006) apresentou, em 1959, seus 18 happenings em 6 partes, na Reuben Gallery em NY Uma proposta artística montada em formato de colagem de acontecimentos, com o salão dividido em partes por plásticos transparentes. Em cada parte havia cadeiras para o público e espaço para o performer. As performances acontecem simultaneamente com três happenings em cada parte. O espectador podia trocar de "parte" a qualquer momento, desde que seguisse algumas regras que eram entregues 
happenings, admitia a coexistência de diferentes sistemas em uma mesma moldura estética, ou mesmo uma multiplicidade de molduras se alternando ao longo do acontecimento. O evento teatral é pensado como um conjunto de transações relacionadas, no qual todo o espaço é utilizado para a performance, o foco é flexível e variável, todos os elementos da produção falam sua própria linguagem e o texto não tem primazia (Schechner, 1994, p.xix-xiv).

O teatro de imersão, termo que designa o trabalho de grupos atuais como Big Art Group, Blast Theory, Kondition Pluriel, Performance Collective Urland, Lemíeux Pilon 4D $\mathrm{Art}^{5}$ e o próprio Sleepwalk Collective, com o qual estivemos em contato, pode ser compreendido parcialmente como desdobramento mais recente das premissas lançadas por Kaprow e Schechner. A imersão buscada nesses trabalhos é especialmente sensorial e acontece na temporalidade do aqui e agora, destacando o momento presente como um acontecimento do mundo real. É através da hipermediação que se revelam os meios e o processo de mediação executados, que o(a) ator(atriz) estimula o(a) espectador(a) a se tornar participante da obra. Quanto maior for a intensidade da experiência cênica, maior será o grau de imersão sensorial do(a) espectador(a).

Para alcançar essa imersão, existem "quatro elementos fundamentais: tempo, espaço, presença e manipulação de sentidos que, de acordo com tratamentos específicos, fundam a composição cênica de caráter imersivo" (Casiraghi, 2017, p.26). Assim, todo o processo de criação em formato cênico intimista precisa estar pautado na experiência do(a) espectador(a):

É muito importante quando está fazendo este trabalho, se deslocar para dentro e para fora constantemente. Temos que ser o agente que está fazendo, mas temos que nos colocar como público para entender como público recebe esse estímulo ou essa ação que você está propondo. É muito importante esse deslocamento: dentro e fora. Através desse deslocamento, vai desenvolver técnicas de manipulação física e passará a entender como se pode atingir o que está propondo (Solano, 2020, informação verbal). 
A proposta prática na oficina ministrada pelo Sleepwalk Collective e nos exercícios desenvolvidos pelo grupo de estudos e práticas durante o projeto de iniciação científica garantiu esse deslocamento entre o fazer e o experimentar. Ao optarmos por explorar esse formato de forma coletiva e compartilharmos nossas cenas, passamos pelas duas experiências: ator/atriz e espectador(a). Essa dinâmica permitiu reflexões acerca do conceito de imersão e dos papéis e significações dos elementos cênicos:

Na prática teatral contemporânea, o ator não remete mais sempre a uma pessoa verdadeira, a um indivíduo formando um todo, a uma série de emoções. Não significa mais por simples transposição e imitação; constrói suas significações a partir de elementos isolados que toma emprestado de partes de seu corpo (neutralizando todo o resto): mãos que mimam uma ação inteira, boca unicamente iluminada com exclusão de todo o corpo, voz do narrador que propõe enredos e representa sucessivamente vários papéis (Pavis, 1996, p.55).

A proximidade da cena intimista é uma grande aliada para construir novas significações em elementos teatrais. Em uma experiência realizada no grupo de pesquisa durante a iniciação científica, a bolsista Bianca utilizou da proximidade para que o(a) espectador(a) acompanhasse sua narrativa a partir de uma perspectiva linear. Como em uma exposição, cada momento da obra se encontrava em uma área delimitada no espaço cênico e, para acompanhar aquele momento, era necessário que o(a) espectador(a) estivesse próximo e com a atenção voltada para os elementos presentes naquele foco delimitado. Dessa forma, mesmo utilizando vários elementos, foi possível conduzir o(a) espectador(a) para elementos específicos em momentos determinados da cena. Mas é importante ressaltar que mesmo a proximidade e a construção de novas significações não garante profundidade à obra:

É muito perigoso que nos formatos cênicos de imersão, intimistas, fiquemos na superfície, isso é muito fácil. Vamos criar uma festa para um café, porém não tem profundidade. Isso não vale, para isso temos outros tipos de manifestações. Não podemos desperdiçar, não podemos perder a oportunidade de se produzir um encontro, de se produzir uma transformação, de se produzir uma experiência. Temos que buscar isso, e para isso é necessário profundidade. Te diria que profundidade permite trabalhar com materiais que são potencialmente inflamáveis. Mas tente 
criar mecanismos para que o público possa atravessar sem sequelas (Solano, 2020, informação verbal).

A profundidade da imersão sensorial pode provocar inúmeras reações em um público que está a uma distância curta de um acontecimento que pretende ser intenso. É preciso criar mecanismos que garantam ao(à) espectador(a) a entrada e saída da obra, evitando situações em que ele(a) se sinta coagido ou desrespeitado. No contexto de nosso grupo de estudos e práticas artísticas, o professor mestre Marcial de Asevedo usou da nudez em seu experimento cênico. A ação era realizada enquanto o(a) espectador(a), como parte da proposta cênica, lia o trecho de um livro. Considerando as diversas atitudes que diferentes os(as) espectadores(as) possam ter sobre a nudez, essa configuração pode criar uma ponte entre ser profundamente provocado(a), mas permanecer imerso na experiência proposta pela cena.

Em uma proposta cênica intimista, o(a) espectador(a) não contempla materiais cênicos à distância, mas vivencia uma experiência de encontro e imersão. O mecanismo para que essa experiência aconteça, como articula Solano, sem sequelas para o(a) espectador(a), é uma escolha subjetiva pertinente a cada processo e objetivo cênico, mas a ética é algo imprescindível em qualquer obra. Não se trata de moral, mas de uma ética que

se encontra na ação. Não é pensando, não é uma coisa que eu decido as regras do que se pode ou não se pode, por medo de como vai afetar a peça, o público. Eu creio que é muito importante que seja permitido propor coisas que podem ser efetivamente perigosas, sempre que criamos mecanismos de suporte (Solano, 2020, informação verbal).

É preciso pensar, antes de tudo, no(a) espectador(a) e no que está sendo proposto como experiência para ele(a).

\section{Em direção a uma cena intimista remota}

Com advento da pandemia de Covid-19 e das medidas restritivas adotadas no Brasil a partir de março de 2020, o trabalho presencial desenvolvido em nosso 
grupo de estudos e práticas artísticas da cena intimista foi interrompido. A princípio, a pesquisa prosseguiu na frente bibliográfica e com a realização de entrevista com a artista lara Solano, do Sleepwalk Collective. Entretanto, a fim de concluir o plano de trabalho da iniciação científica, logo fomos confrontados com o desafio de prosseguir com as práticas criativas. Uma nova questão se impunha: como fazer teatro, teatro de imersão, cena intimista em formato remoto?

Nos últimos meses do plano de trabalho da iniciação científica, e ainda tateando diante da perplexidade com as limitações impostas pela pandemia, criamos uma vídeo-cena. Posteriormente, retomamos a temática por meio do plano de trabalho intitulado A cena intimista e sua paisagem sonora, com apoio do Programa Institucional de Bolsas de Extensão, da Universidade Federal do Tocantins. Dentro desse plano de trabalho, vigente no período de abril a dezembro de 2021, criamos um episódio de podcaste uma cena de áudio-teatro interpretada remotamente de maneira síncrona. Para situar essas práticas e seus resultados, faz-se necessário retomar a reflexão sobre a natureza do teatro, as implicações do uso de tecnologias e as possibilidades para criadores cênicos no contexto da pandemia.

Figura 1 - captura de tela da vídeo-cena Saudade (2020)

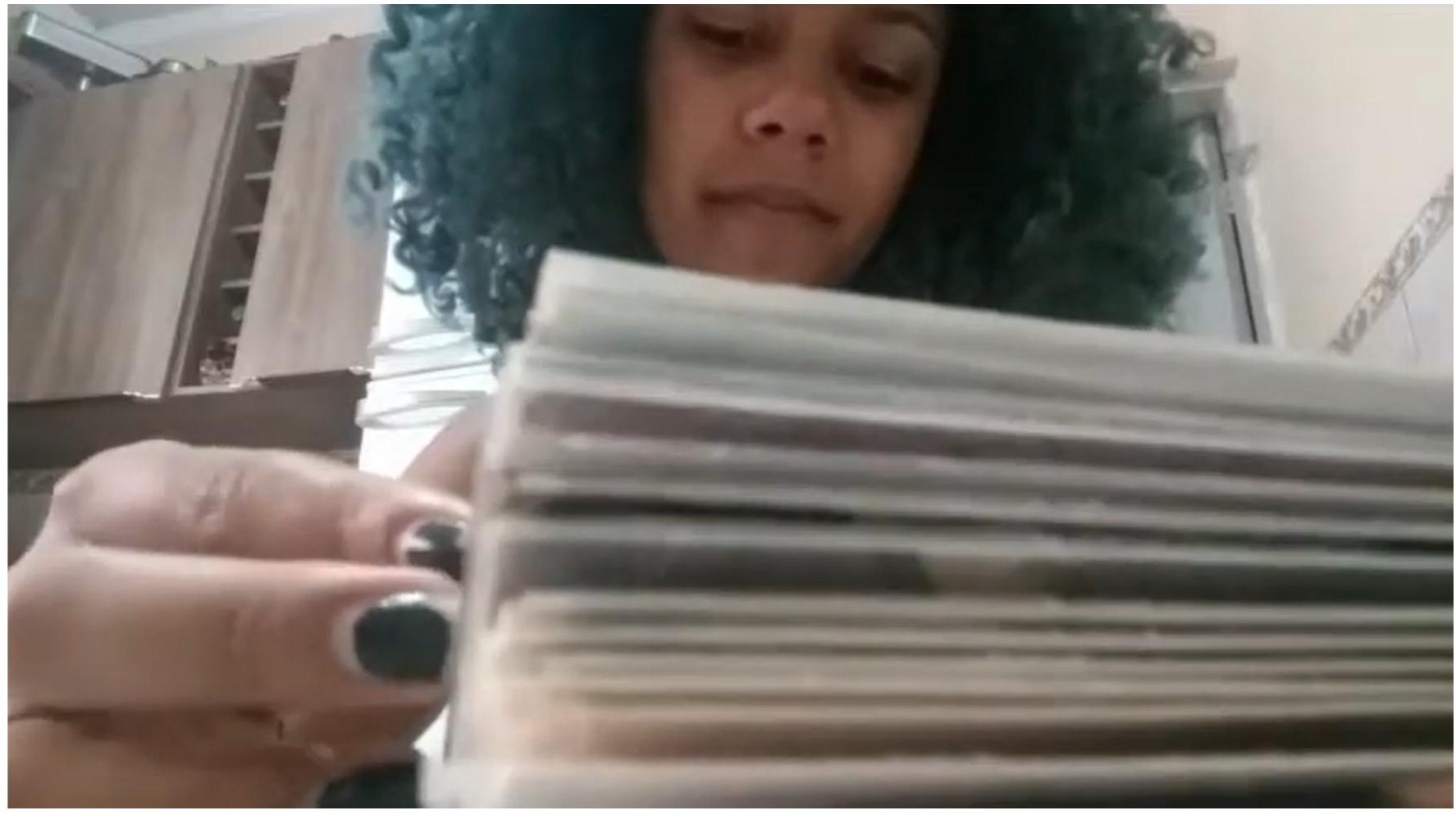


O crítico e teórico argentino Jorge Dubatti tem discutido a própria noção de teatro, suas condições de existência e seu significado humano e político frente ao avanço das tecnologias contemporâneas de comunicação. Ele conceitua convívio como característica fundante do teatro, enfatizando que

el convivio, manifestación ancestral de la cultura viviente, diferencia al teatro del cine, la televisión, la radio, el skype y el chateo, porque el teatro exige la presencia viva, real, de cuerpo presente, de los artistas, en reunión con los técnicos y los espectadores (Dubatti, 2015, p.45).

A posição do autor é clara: "En tanto acontecimiento, el teatro es algo que existe mientras sucede, y en tanto cultura viviente no admite captura 0 cristalización en formatos tecnológicos" (Dubatti, 2015, p. 45). Assim, do ponto de vista ontológico exposto pelo autor, a distinção entre o convívio de pessoas em presença física e o tecnovívio, produzido pelas presenças telemáticas ou virtuais, é fundamental para a compreensão da própria noção de teatro.

Indo além, Dubatti argumenta que "La situación tecnovivial implica una organización de la experiencia determinada por el formato tecnológico (Dubatti, 2015, p.46). O tecnovívio subtrai a zona vital de experiência do convívio e adiciona uma série de recortes e a hierarquização do acesso à informação, devido aos interesses comerciais e aos custos envolvidos na aquisição, manutenção e funcionamento do aparato técnico. Portanto, do ponto de vista político, Dubatti se posiciona em favor da valorização e defesa do convívio através do teatro.

Ainda assim, escrevendo sobre o tema antes do advento da pandemia de Covid-19, Dubatti já admitia a coexistência e o hibridismo entre os dois paradigmas na vida contemporânea e na experiência teatral (Dubatti, 2015, p.49). Naquele contexto, discutia o teatro neo-tecnológico, que experimentava cruzamentos entre tecnovívio e convívio no espaço teatral. Tratando do espetáculo Distancia (2013)6 do diretor argentino Matías Umpierrez, concluía: "Paradójicamente, Distancia transforma el tecnovivio en poética teatral para exaltar el valor del convivio ancestral, la antigua escala de lo humano" (Dubatti, 2015, p.53). Portanto, naquele 
contexto, Dubatti exaltava a capacidade do teatro para ressignificar o tecnovívio, ao assimilá-lo à potência do convívio.

O teatro de imersão presencial configura-se, em muitos casos, como um teatro neo-tecnológico, agregando dispositivos como parte de sua abordagem voltada para a imersão sensorial. Assim, no processo de composição cênica do teatro de imersão presencial, o uso da tecnologia "exige uma investigação de como os dispositivos interferem na percepção do sujeito" (Casiraghi, 2017, p.14). O que se busca, nesse caso, é produzir processos de desorientação (Casiraghi, 2017, p17) quanto aos elementos espaço, tempo, presença ou percepção sensorial.

No espetáculo The Sirens vis-à-vis, o Sleepwalk Collective utiliza um dispositivo de transmissão sonora. A atriz fala em um microfone e sua voz, mixada à trilha sonora pré-gravada, chega ao(à) espectador(a) por meio de fone de ouvido sem fio. Em alguns momentos, a voz é submetida a processamentos de áudio, com efeitos de tempo (reverberação, delay) e de modulação. Nessa experiência, o inundamento auditivo e a mediação tecnológica geram desorientação quanto ao espaço e à presença, proporcionando ao(à) espectador(a) uma sensação de irrealidade e imersão.

Assim, o teatro imersivo e a cena intimista presenciais, como o teatro neotecnológico descrito por Dubatti (2015), se valem da assimilação de elementos tecnológicos ao convívio teatral para atingir seu objetivo de estimulação e imersão sensorial. Mas como transpor essas abordagens para um processo criativo exclusivamente remoto?

Ao retomar a distinção entre convívio e tecnovívio após a experiência de isolamento social provocada pela pandemia de Covid-19, Dubatti (2020) atualiza a discussão, levando em conta as necessidades criativas e econômicas que se impuseram aos artistas de teatro, nesse novo contexto. Volta a asseverar o posicionamento político em favor do convívio como característica fundamental do teatro e da experiência humana. Entretanto, admite as possibilidades criativas das experiências artísticas em tecnovívio (Dubatti, 2020, p.30).

Para esclarecer essa posição, deve-se compreender como Dubatti delimita as características fundantes do teatro. Ele define ontologicamente o teatro como 
acontecimento, no qual, além do convívio, há outras duas condições mínimas para gênese e concretização da experiência teatral: uma poética corporal, produzida pelo ator ou performer, e a expectação, ação do(a) espectador(a) (Dubatti, 2020, p.14-15). Se, por um lado, conforme a argumentação exposta anteriormente, o tecnovívio é incompatível com o convívio, subtraindo essa característica fundante do teatro, por outro lado, a poética corporal e a expectação podem ocorrer em mediação tecnológica. Assim, privados das atividades com presença física, os criadores cênicos passam a produzir poéticas corporais e os(as) espectadores(as) a expectar por meio de presenças telemáticas ou virtuais.

Aí está o campo que Dubatti (2020, p.16) denomina de artes tecnoviviais. Entre as artes tecnoviviais e o teatro não há identidade, nem competição, nem superação, nem evolução. Há, entretanto, uma relação assimétrica, tendo em vista que o convívio teatral pode assimilar o tecnovívio, ou elementos dele, mas o oposto não pode ocorrer. A situação implica em pluralismo de experiências artísticas, diversidade de epistemologias, multiplicidade de formações e campos de atuação para artistas e de oportunidades de fruição para espectadores(as) (Dubatti, 2020, p.23-24).

Admitindo essa pluralidade, na segunda etapa de nosso percurso de criação, processo formativo e construção de conhecimento, buscamos trazer elementos de teatro imersivo e cena intimista para as práticas criativas remotas. Na vídeocena Saudade $(2020)^{7}$, que foi elaborada na conclusão do plano de trabalho de iniciação científica, com textos de caráter autoficcional, buscava-se remeter à ideia de proximidade por meio do posicionamento da câmera, permitindo ao(à) espectador(a) ora colocar-se no ponto de vista da atriz, ora ver-se diante da atriz, num ponto de vista vis-à-vis. Notamos também que o posicionamento próximo da câmera permitia captar sons produzidos pela manipulação de objetos, construindo uma paisagem sonora que também contribuía para a construção da sensação virtual de proximidade.

A partir da constatação de que a sonoridade é fundamental para a transposição da ideia de cena intimista para uma prática criativa mediada pelas

${ }^{7}$ Disponível em: https://www.youtube.com/watch?v=ivp2t3NtLHM. Acesso em: 10 jun. 2021. 
tecnologias remotas, passamos a desenvolver uma exploração mais intencional desse elemento, como parte de nosso processo criativo. A sensação auditiva de proximidade, proporcionada pela escuta de sons suaves presentes em ambientes domésticos ou produzidos pela manipulação de objetos cotidianos, é um ponto de partida dessa exploração. Outro ponto de partida e referencial que adotamos é o uso que o Sleepwalk Collective faz de sons contínuos na construção de suas trilhas sonoras pré-gravadas. Esses sons contínuos possuem caráter quase hipnótico, manipulando a atenção auditiva - na medida em que mascaram ruídos do ambiente real em que se encontra o(a) espectador(a) - e gerando uma sensação de estase, suspensão dramática.

Outro importante aspecto da avaliação da vídeo-cena foi a consideração sobre o tipo de relação a ser estabelecida com o(a) espectador(a). Se no teatro imersivo e no formato cênico intimista o(a) espectador(a) deve ser entendido como parte ativa da obra, as mídias gravadas, mesmo que buscando reproduzir características de visualidade e sonoridade de uma experiência imersiva presencial, não permitem estabelecer relações e trocas. Essa constatação fundamenta a tomada de posição de construir uma proposta cênica remota de caráter síncrono, a despeito dos riscos e instabilidades das conexões virtuais em tempo real.

Assim, para o plano de trabalho da bolsa de extensão, vigente de abril a dezembro de 2021, tomamos os textos escritos por Bianca para a vídeo-cena como ponto de partida para uma remontagem expandida e síncrona. Ao mesmo tempo, assumimos que as múltiplas mídias geradas na dinâmica do trabalho em tecnovívio - imagens, áudios, vídeos - podem ser tanto agregadas ao resultado final desejado, quanto compartilhadas nos espaços virtuais como resultados parciais de um processo criativo que gera múltiplos produtos. Assumimos, portanto, como em outras vivências teatrais universitárias durante a pandemia, a condição experimental da proposta, com suas fragilidades e possibilidades, numa abordagem que, apesar de "não repetir modelos ou estruturas da presencialidade", busca "traçar caminhos homólogos" aos objetivos iniciais (Gómez e Dip, 2020, p.144).

Como primeiro exercício dessa nova etapa, Bianca utilizou seu dispositivo móvel para registrar imagens (fotografia) e sons (gravação de áudio digital) que 
poderiam contribuir na construção de texturas visuais e sonoras para a remontagem síncrona. Duas das imagens foram compartilhadas pelo perfil de Instagram do projeto de extensão Oficina de Criatividade Sonorå. E um dos sons gravados foi o ponto de partida para a construção da composição sonora Goteira ${ }^{9}$, veiculada em episódio de podcast do mesmo projeto. Na faixa sonora, o som referenciado no título da peça foi gravado em ambiente doméstico e é acompanhado por um som harmônico contínuo, que Heitor compôs por meio da sobreposição e processamento digital de notas sustentadas em flauta irlandesa. Ao final, a voz da atriz é brevemente adicionada à textura com um fragmento de texto.

Figura 2 - fotografia produzida por Bianca de Melo no levantamento de imagens para a concepção de cena intimista em formato remoto

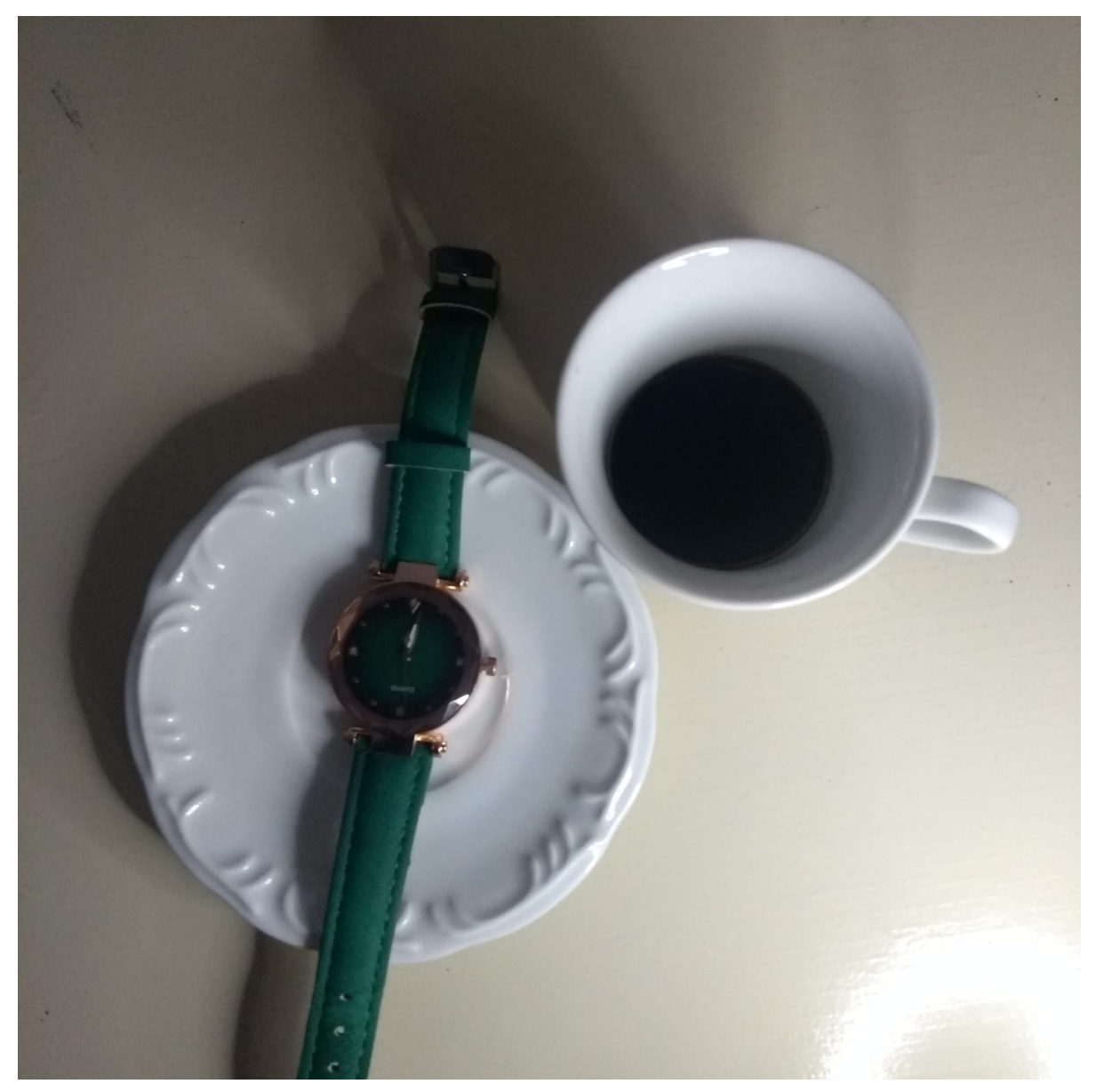

${ }^{8}$ Disponível em: https://www.instagram.com/ocris.uft/. Acesso em: 14 jun. 2021.

9 Disponivel em: https://anchor.fm/heitor-ocris/episodes/Goteira-e10cvs3. Acesso em: 14 jun. 2021. 
Na medida em que reflete também "uma mudança causada pela pandemia e pelo isolamento social nos ambientes sonoros", essa composição, com caráter de paisagem sonora, busca denotar uma experiência compartilhada de "como as pessoas se adaptaram ao isolamento social" (Pédico, Machado e Souza, 2020, p.321). Por capturar expressivamente essa experiência, a composição cria um ambiente sonoro que adotamos para a imersão sensorial que pretendemos criar em nosso primeiro experimento síncrono com audiência ${ }^{10}$.

Nesse experimento, a fim de construir um domínio gradativo dos dispositivos, optamos pelo formato áudio-teatro ${ }^{11}$, aqui entendido como uma espécie de teatro cego virtual, como aquele realizado pelo grupo de Teatro Oscuro de Tandil (Argentina), na série Todo que oír (2020)12. A diferença é que, em nossa proposta, a áudio-cena é performada ao vivo, unindo transmissão da voz em tempo real e trilha sonora pré-gravada e prevendo uma expansão posterior, na qual esse material passará a ser parte de uma peça mais longa com cenas que incluirão transmissão de vídeo.

Ou seja, do ponto de vista técnico, pretendia-se também selecionar e experimentar o uso de uma plataforma que, tendo atriz e espectador(a) em uma mesma sala virtual, permitisse a administração do que está sendo colocado em tela, inclusive com possíveis alternâncias e sobreposições de capturas de áudio e vídeo em tempo real e imagens, vídeos e áudios pré-gravados. Adotamos a versão gratuita da plataforma Stream Yard, utilizando o estúdio como sala virtual restrita.

Nesse experimento em áudio-teatro, o trabalho com a voz da atriz foi o principal elemento da proposta criativa a ser desenvolvido.

a voz, aparentemente nosso portal rumo à possibilidade de uma comunicação efetiva, passa por uma prova nunca antes vivida com tanta

10 Disponível em: https://www.youtube.com/watch?v=cisriXIhF24. Acesso em: 15 jun. 2021. O vídeo contém três iterações do experimento e conversas com cada espectadora.

${ }^{11}$ Correia e Santos (2020) abordam uma experiência com rádio-teatro no ensino remoto, apresentando um histórico do gênero e a diversidade de nomenclaturas correlatas.

12 Episódios disponíveis em <https://youtu.be/yamnzYvzIMk> (1) e em <https://youtu.be/6 OkLLLULs4> (2). Acesso em: 15 jun. 2021. 
intensidade. nossa voz não faz eco. é filtrada por filtros indesejáveis e é achatada ao plano bidimensional do contato pela tela e se depara engessada na digitalização de ondas sonoras com efeito subtrativo de sons harmônicos e de sons resultantes. escutamos apenas um fio do tecido das ondas sonoras. (Diniz e Goussinsky, 2020, p. 293; grafia sem maiúsculas no original)

Ao admitir a filtragem, a bidimensionalidade e a instabilidade da voz em rede, optamos por explorar possibilidades proporcionadas pela mediação tecnológica, como afastamento ou proximidade ao microfone e a dualidade entre transmissão de vocalização em tempo real e transmissão da voz pré-gravada e submetida a processamentos de áudio digital. Nesse contexto, assim como em outras experiências similares, a atriz depara-se com um "sistema de trabalho baseado em reconhecer suas vocalidades e trabalhá-las usando a gravação, o microfone e a arte sonora como meio ou como um fim" (Spritzer, 2014, p.91). Assim, os recursos inerentes à mediação tecnológica da voz pontuam a oralidade da atriz na performance do texto e constituem uma das camadas de sentido e dinâmica sonora da áudio-cena.

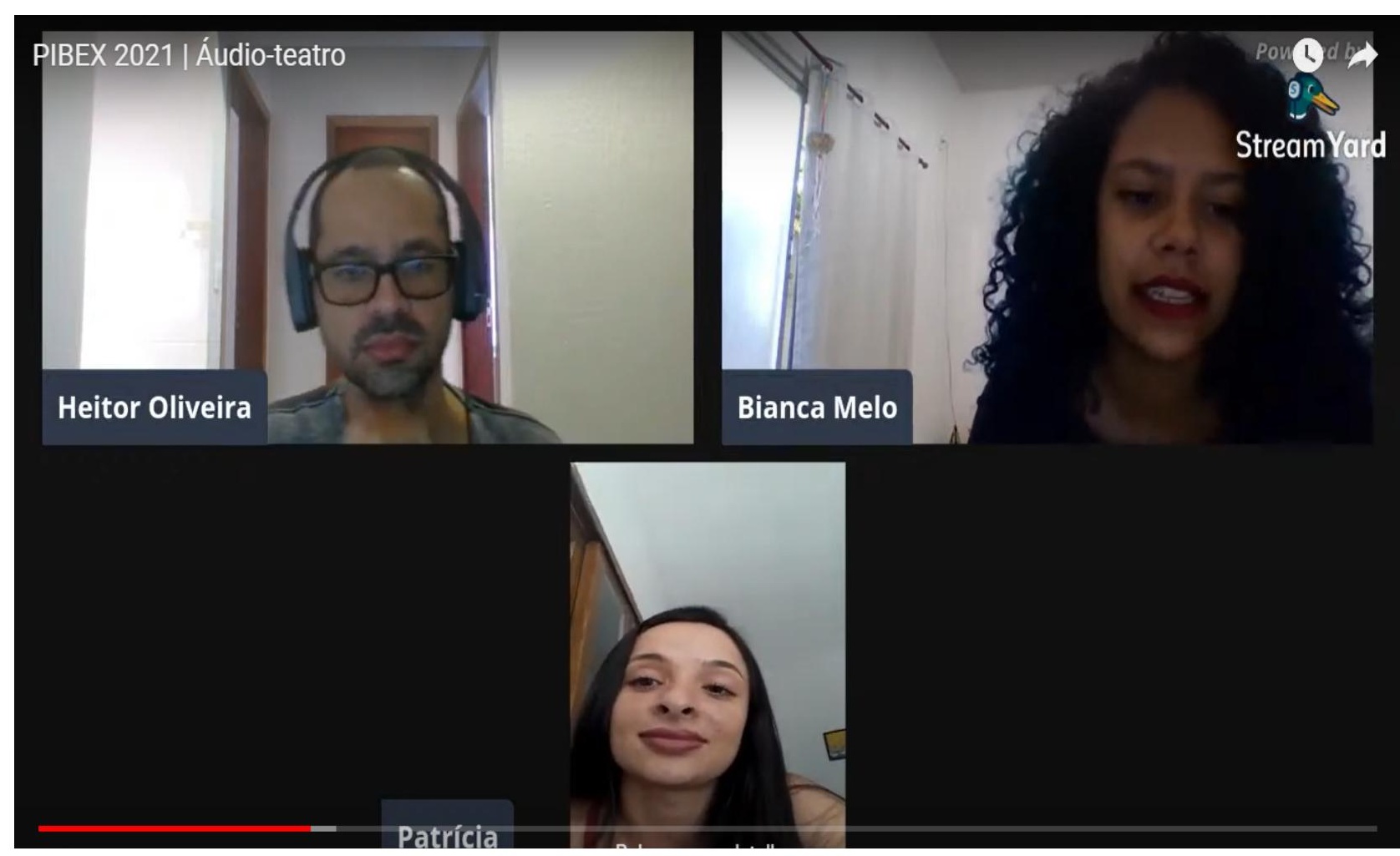


O retorno obtido de três espectadoras, que participaram individualmente do experimento em áudio-teatro virtual síncrono, é importante para situarmos a experiência que a criação proporciona e entender quais elementos podemos explorar em maior escala.

O retorno da espectadora Patrícia de Sá nos confirma a potencialidade da imersão sonora por meio do trabalho vocal da atriz: "[...] é como se uma voz consciente estivesse falando com você [...] alguém falando no pé do seu ouvido, como se fosse uma voz do subconsciente. A parte do sussurro traz muito arrepio [...] É como se estivesse bem próximo de você a pessoa, a voz presente."

Já o retorno de Ana Kamila nos revela a potencialidade dos sons e como eles podem convergir junto com a voz para a imersão sensorial: "[...] todos esses sons, motiva a gente a vivenciar essa narrativa, os sons ajudam muito a viver, a sentir mesmo o que ela fala [...]". A sonoplastia e a paisagem sonora criadas por meio de recursos tecnológicos complementam a proposta imersiva.

Outra característica importante para a qualidade de imersão é a temporalidade. Como afirma a espectadora Flaviana OX: "queria continuar [ouvindo]. Senti vontade de continuar, estava gostoso". Esse retorno permite relacionar a imersão sensorial auditiva a uma desorientação da espectadora quanto ao tempo. Sustentar essa imersão é um desafio e somente é possível dimensionar a intensidade da experiência e a capacidade temporal desta, quando se coloca o experimento à prova, quando se está no tempo real do acontecimento cênico.

\section{Considerações finais}

Para responder ao questionamento inicial sobre a natureza e possibilidades de um processo criativo remoto que tem como proposta a noção de cena intimista, foi necessário reavaliar as práticas cênicas presenciais e, em seguida, explorar mecanismos do fazer artístico em espaços virtuais. Assim, a reflexão sobre os primeiros experimentos práticos presenciais em cena intimista, foram imprescindíveis para uma clara definição dos limites entre o teatro tradicional e o 
teatro de imersão. Quanto à organização do espaço, o teatro tradicional é um formato de estrutura pouco flexível que se vale da separação entre palco e plateia e prioriza a construção de signos para leitura de seus elementos. O teatro de imersão, por sua vez, possui uma variedade de estruturas possíveis, inclusive possibilitando a exploração do contato físico e da imersão sensorial. Sem a compreensão das diferenças entre um e outro, o processo de criação se torna penoso e pouco produtivo, pois corre-se o risco de propor uma experimentação intimista a partir de um processo tradicional. É preciso entender as possibilidades de novos signos para o espaço, tempo e presença e abrir-se à exploração de elementos que manipulem os sentidos, intencionando modos próprios de desorientação e a construção de uma experiência única de encontro.

Ao transpor essas considerações para a criação artística em formato remoto, em que pese as limitações do tecnovívio, concluímos que a homologia mais adequada para o tipo de cena intimista que buscamos é a transmissão síncrona em sala virtual na qual ingressam apenas a atriz (estudante, bolsista), o(a) espectador(a) e um responsável pelo suporte técnico (professor, orientador). Nesse encontro virtual, há condições para criar uma moldura e manipular dispositivos com objetivos estéticos similares aos da cena intimista presencial. Nossas experiências iniciais destacam ainda a pertinência de transformar os múltiplos registros do processo criativo em formato remoto em material para compartilhamento de resultados parciais, para avaliação e reflexão sobre o próprio processo.

A pertinência é ainda mais significativa por se tratar do registro e reflexão sobre processos formativos desenvolvidos no período de atividades acadêmicas emergenciais remotas. Constituem, portanto, contribuições para experiências em pesquisa e extensão universitária nesse contexto, ao apontar alternativas da construção de conhecimento e de interface com a comunidade. Ademais, os dispositivos e as reflexões desse mesmo processo proporcionam uma ampliação de contextos de formação e atuação artística. 


\section{Referências}

CASIRAGHI, Mauricio Pezzi. Insônia: A tecnologia audiovisual como catalisadora para a imersão no teatro. Dissertação (Mestrado em Artes Cênicas) - Universidade Federal do Rio Grande do Sul, Porto Alegre, 2017.

CORREIA, Eliana Rosa; SANTOS, Gleiziane Pinheiro dos. O rádio-teatro no ensino remoto: um experimento artístico-pedagógico. Rebento, São Paulo, n. 13, p.325346, jul. - dez 2020. Disponível em:

http://www.periodicos.ia.unesp.br/index.php/rebento/article/view/596.

Acesso em: 14 jun. 2021.

DINIZ, Liana Ferraz; GOUSSINSKY, Sônia. A voz em (instabilidade de) rede. Rebento, São Paulo, n. 13, p.285-303, jul. - dez 2020. Disponível em http://www.periodicos.ia.unesp.br/index.php/rebento/article/view/584. Acesso em: 14 jun. 2021.

DUBATTI, J. Convivio y tecnovivio: el teatro entre infancia y babelismo. Revista Colombiana de las Artes Escénicas, v. 9, p.44-54, 2015.

DUBATTI, Jorge. Experiência Teatral, experiência tecnovivival: nem identidade, nem campeonato, nem melhoria evolutiva, nem destruição, nem laços simétricos. Rebento, São Paulo, n. 12, p. 8-32, jan. -jun. de 2020.

GÓMEZ, Máximo José; DIP, Nerina Raquel. Da contenção à criação: experiência artístico-pedagógica na pandemia. Tradução: Simone Carleto. Rebento, São Paulo, n. 13, p. 139-163, jul. - dez 2020. Disponível em http://www.periodicos.ia.unesp.br/index.php/rebento/article/view/603. Acesso em: 14 jun. 2021.

SCHECHNER, Richard. Environmental theater. New, expanded ed. New York: Applause, 1994.

PAVIS, Patrice. A análise dos espetáculos: teatro, mímica, dança, dança-teatro, cinema. Tradução: Sérgio Sálvia Coelho. São Paulo: Perspectiva, 2011.

PÉDICO, André Leme; MACHADO, Fabiana de Sousa Cunha; SOUZA, Leandro Pereira de. As Oficinas "Paisagem Sonora - Sons e Silêncios da Quarentena": relato de experiência realizada na Mostra Virtual de Artes do CEFET-MG. Rebento, São Paulo, n. 13, p. 304-324, jul. - dez 2020. Disponível em: http://www.periodicos.ia.unesp.br/index.php/rebento/article/view/594. Acesso em: 15 jun. 2021.

SOLANO, Iara. Formato Cênico Intimista. Entrevista cedida a Bianca Nascimento de Melo. Palmas (TO), 12 ago. 2020. Transcrita em anexo do relatório final do projeto de iniciação científica: Processo de criação em cena intimista: narrativas de uma artista-pesquisadora em formação, pela Universidade Federal do Tocantins (UFT, 
2019-2020).

SPRITZER, Mirna. O exercício radiofônico como prática da palavra, da vocalidade e da escuta. Urdimento - Revista de Estudos em Artes Cênicas, Florianópolis, v. 1 n. 22, p. 89-98, julho de 2014.

Disponível em:

https://www.revistas.udesc.br/index.php/urdimento/article/view/141457310122201 4089/3178. Acesso em: 14 jun. 2021.

Recebido em: 15/06/2021

Aprovado em: 15/10/2021 